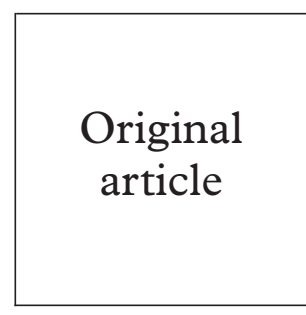

Department of Obstetrics and Gynaecology, Örebro Medical Centre Hospital, Örebro, Sweden

F Kamwendo L Forslin

Unit of Biostatistics and Epidemiology L Bodin

Department of Clinical Microbiology and Immunology D Danielsson

Centre for Assessment of Medical Technology L Bodin

D Danielsson

Correspondence to: Francis Kamwendo, Örebro Medical Centre Hospital, S-701 85 Örebro, Sweden

Accepted for publication 5 November 1999

\title{
Epidemiology of ectopic pregnancy during a 28 year period and the role of pelvic inflammatory disease
}

F Kamwendo, L Forslin, L Bodin, D Danielsson

Objectives: We analysed the epidemiology of ectopic pregnancy (EP) during a 28 year period, 1970-97, using methods applicable to ecological studies in order to test the hypothesis that a reduction of pelvic inflammatory disease (PID) will be associated with a decrease of EP.

Methods: Hospital records of patients aged 15-54 admitted to our department of gynaecology were reviewed for EP and PID for the period 1 January 1970 to 31 December 1997. EP for the period 1970-4 was based on available statistics. The total number for EP was 1270 and for PID 2559. The total population for the catchment area was $100000-120000$ during the study period. Incidences were age standardised and calculated using official population statistics to represent the average female population in the five 5 year periods 1970-4, 1975-9, 1980-4, 1985-9, 1990-4, and in each of the consecutive years 1995, 1996, and 1997. Incidences for EP were calculated per 1000 women and per 1000 pregnancies while those for PID per 1000 women. National statistical data of EP were available for 1975-94 and were used for comparison with the local study.

Results: The EP incidences increased from 7.7 per 1000 pregnancies in the first 5 year period to 13.4 in the second, and continued to rise for another decade reaching the peak figures of 16.6 in 1985-9 - that is, more than a twofold increase. Since then and to 1997 the EP incidence has decreased by $30 \%$. PID admissions increased during the study period from 2.7 per 1000 women in the first 5 year period to 3.2 in the second. From then on they continuously decreased and reached a low of 0.5 in 1997 . The greatest changes occurred in women $\leqslant 24$ years of age. The peak incidence for this age group was 7.7 in 1975-9, and the lowest was 0.4 per 1000 women in 1996. The greatest reduction of EPs was noted for women $\leqslant 24$ years old, from a high of 10.0 in 1975-9, coinciding with the peak incidence of PID, to a low of 4.0 in 1997, a reduction of $58.4 \%$. The incidence of EP was two to three times higher in women $\geqslant 25$ years old, most obvious in those $\geqslant 30$ years, with peak figures of 20.9 per 1000 pregnancies in 1985-9, and 13.9 in 1997, a reduction of $33.4 \%$ and the lowest figures for the past 23 years. For women aged 25-29 years the incidence peaked in the previous 5 year period 1980-4- that is, one 5 year period later than for those $\leqslant 24$ years, which we interpret as cohort effects in relation to PID.

Conclusions: Reduction of PID was strongly associated with a decline of EP. The decline was greater and immediate for women $\leqslant 24$ years old, than for those $\geqslant 25$ years. The two to three times higher EP incidence in women $\geqslant 25$ years of age was most probably due to a cohort effect as the peak of PID occurred a decade earlier in women $\leqslant 24$ years old. Prevention of PID may not only reduce EP but also reduce adverse effects on tubal patency.

(Sex Transm Inf 2000;76:28-32)

Keywords: ectopic pregnancy; pelvic inflammatory disease; gonorrhoea; Chlamydia trachomatis, sexually transmitted disease; Sweden

\section{Introduction}

Ectopic pregnancy (EP) - that is, implantation of a fertilised egg outside the uterine corpus, is presented as an acute emergency and a life threatening event, accounting for up to about $10 \%$ of all maternal mortality. ${ }^{1-3}$ Several publications have documented twofold to fourfold increases of EP rates during the past three decades in many parts of the world, including various European countries, ${ }^{4-7}$ North America, ${ }^{8-10}$ Australia, ${ }^{11}$ and Saudi Arabia. ${ }^{12}$ Incidence figures of 19.7 per 1000 pregnancies were reported from the United States in 1992, their highest level in more than two decades. ${ }^{13}$

The pathogenesis of EP is considered multifactorial ${ }^{14}{ }^{15}$ with incidence usually lower in women $\leqslant 24$ years old. ${ }^{16}{ }^{17}$ However, postinflammatory lesions of the fallopian tubes due to an ascending infection from the lower geni- tal urinary tract are a major aetiological factor. In fact, a previous pelvic inflammatory disease (PID) has been shown to be the strongest predictor. $^{4111517}$

There were several reports of increasing incidences of overt PID during the 1960s and 1970s in the United States and Europe, ${ }^{18-20}$ including our own area. ${ }^{21}{ }^{22}$ However, we still had relatively few reported incidences of EP, 7.7 per 1000 pregnancies during the 5 year period 1970-4. Five years later the corresponding figure was 13.4, an increase of almost $72 \%$. PID incidences, however, started decreasing steadily in the mid 1980s in Sweden ${ }^{23}$ and were at their lowest ever in our area during the end of the mid $1990 \mathrm{~s}^{25}$ As there has been proved to be a strong link between PID and EP we wanted to test the hypothesis that a reduction of PID will be associated with a decrease of EP. 


\section{Methods}

PATIENTS AND STUDY PERIOD

The study covers a period of 28 years, from 1 January 1970 to 31 December 1997, of patients admitted and treated for EP or acute PID at the department of obstetrics and gynaecology of Örebro Medical Centre Hospital (ÖMCH). The age span of the patients included in the study was 15-54 years. The catchment area covers Örebro city and its rural surroundings with a total population of 120000 inhabitants. The total population has increased during the study period with approximately $20 \%$ - that is, from about 100000 to the figure given above. The catchment area of the hospital has well defined geographical boundaries that have remained unchanged during the study period. Citizens respect these boundaries for administrative and social reasons. Interflow of patients between neighbouring hospitals is therefore negligible.

For EP, the only source of information available for the period 1970 to 1974 was the statistics of the yearly number of diagnoses without the division into age category or identification of the patients. Tracing the already microfilmed individual patient charts proved difficult and insecure. Hospital records for EP were, however, used for the rest of the study period 1975-97.

CRITERIA FOR DIAGNOSIS

For PID, hospital records were reviewed for the whole study period 1970-97. Diagnostic criteria for PID were reported elsewhere. ${ }^{24}$ In all, there were 2559 admissions for acute PID during the study period.

Ectopic pregnancy was suspected when the patient complained of low abdominal pain and had subjective symptoms of early pregnancy ( $\leqslant 6-7$ weeks) with a positive urine human chorionic gonadotropin (hCG) test. The suspicion of EP was further enhanced if the patient had a previous history of EP, PID, had undergone surgery of the lower abdomen or the fallopian tubes, used an intrauterine contraceptive device (IUCD), had undergone in vitro fertilisation (IVF), used progesterone only preventive pills, or had clinical evidence of vaginal bleeding. When clinical evidence was uncertain, confirmation was made by laparoscopy. For the last decade, we have also used vaginal ultrasound and serial serum hCG (S-hCG). These diagnostic procedures, applied by all physicians at the department of obstetrics and gynaecology, ÖMCH, are in accordance with those used in many other centres. ${ }^{3627}$ In all, there were 1268 admissions for EP during the study period. Two additional patients in 1996 were diagnosed and monitored as outpatients by frequent measurements of S-hCG and the use of vaginal ultrasound. The EPs were finally considered to have terminated as tubal abortions. This gives a total of 1270 EP patients. Our hospital has not yet embarked on a fully fledged outpatient treatment of EP and the cited numbers can therefore be regarded as total incidence for this pregnancy outcome in our catchment area during the study period.
STATISTICS

Incidence was calculated using official population statistics for the catchment area of the hospital to represent the average population in the 5 year periods - $1970-4 ; 1975-9 ; 1980-4$; 1985-9, 1990-4, and each of the consecutive years 1995, 1996, and 1997. The calculation was based on the age range $15-54$ years. The incidences were age standardised. It was in this age range that almost all acute PID and EP occurred. All numbers represent total enumeration within the catchment area during the studied period. In order to obtain incidence based on people the hospital records were examined to accept only one record for each diagnosed individual per year. Those records indicating additional visits or treatments for the same occurrence were rejected. The average number of women in the two age categories for each of the calendar years 1970-97 was about 12000 for those 15-24 years and 35000 for those $25-54$ years.

\section{Results}

The mean incidences in our catchment area of EPs per 1000 pregnancies, and of PID admissions per 1000 women, in total (women 15-54 years) and in the age groups $15-24$ and 25-54, were calculated per 5 year periods and age standardised (fig 1 and table 1). The average number of pregnancies in the two age categories for each of the calendar years 1970 to 1997 was about $800-1300$ for those $\leqslant 24$ years and $2200-2400$ for those $\geqslant 25$ years. In the total number of pregnancies were included deliveries, miscarriages, legal abortions, and ectopic pregnancies.

EPs increased sharply from 7.7 per 1000 pregnancies in the first 5 year period to 13.4 in the second period, and remained high during the following three periods (fig 1). However, EPs dropped by approximately $30 \%$ during the 1990s. During the study period PID admissions increased from 2.7 per 1000 women in the first 5 year period to 3.2 in $1975-9$ when the incidence peaked. From then on they continuously decreased during the following three 5 year periods and the last 3 years to a low of 0.5 , which corresponds to a reduction of $85 \%$.

It is well documented that EPs are more frequent in women $\geqslant 25$ years old than in those

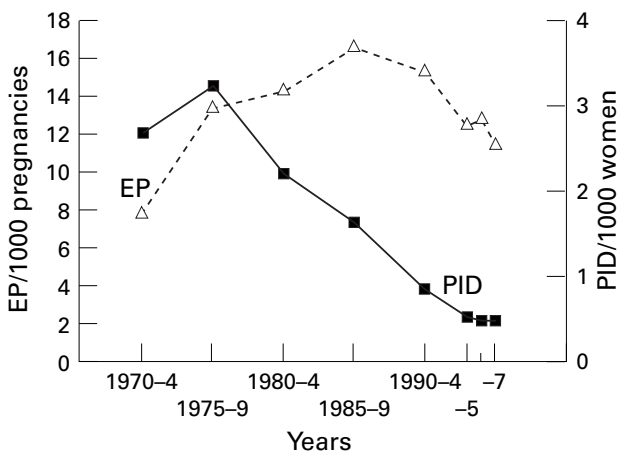

Figure 1 The incidence rates of ectopic pregnancy (EP) per 1000 pregnancies and acute pelvic inflammatory disease (PID) per 1000 women in Örebro county (catchment area for Örebro Medical Centre Hospital) from 1970 to 1997. Incidences were calculated per 5 year period from 1970-94 and then per year from 1995-7. 
Table 1 Incidences of ectopic pregnancy (EP) per 1000 pregnancies, EP per 1000 women and acute pelvic inflammatory disease (PID) per 1000 women in the age groups $\leqslant 24$ and $\geqslant 25$ years in the catchment area of Örebro Medical Centre Hospital for the period 1970-97. Incidences are age standardised and grouped in 5 year periods from 1970 to 1994 and then yearly from 1995 to 1997

\begin{tabular}{|c|c|c|c|c|c|c|}
\hline \multirow[b]{2}{*}{ Time periods } & \multicolumn{2}{|c|}{$\begin{array}{l}\text { EP per } 1000 \\
\text { pregnancies }\end{array}$} & \multicolumn{2}{|c|}{ EP per 1000 women } & \multicolumn{2}{|c|}{ PID per 1000 women } \\
\hline & $\leqslant 24$ years & $\geqslant 25$ years & $\leqslant 24$ years & $\geqslant 25$ years & $\leqslant 24$ years & $\geqslant 25$ years \\
\hline $1970-4^{\star}$ & 7.74 & & 0.49 & & 5.95 & 1.45 \\
\hline $1975-9$ & 10.01 & 15.31 & 0.97 & 0.84 & 7.73 & 1.71 \\
\hline $1980-4$ & 7.45 & 17.50 & 0.68 & 1.17 & 4.52 & 1.41 \\
\hline 1985-9 & 7.28 & 20.95 & 0.73 & 1.59 & 3.39 & 1.01 \\
\hline 1990-4 & 9.85 & 17.53 & 0.88 & 1.23 & 1.55 & 0.63 \\
\hline 1995- & 4.61 & 15.27 & 0.33 & 1.05 & 0.74 & 0.46 \\
\hline 1996- & 4.79 & 15.48 & 0.33 & 0.94 & 0.41 & 0.51 \\
\hline 1997- & 4.02 & 13.85 & 0.25 & 0.78 & 0.67 & 0.43 \\
\hline
\end{tabular}

${ }^{\star}$ Figures for EP could not be stratified for age, see text.

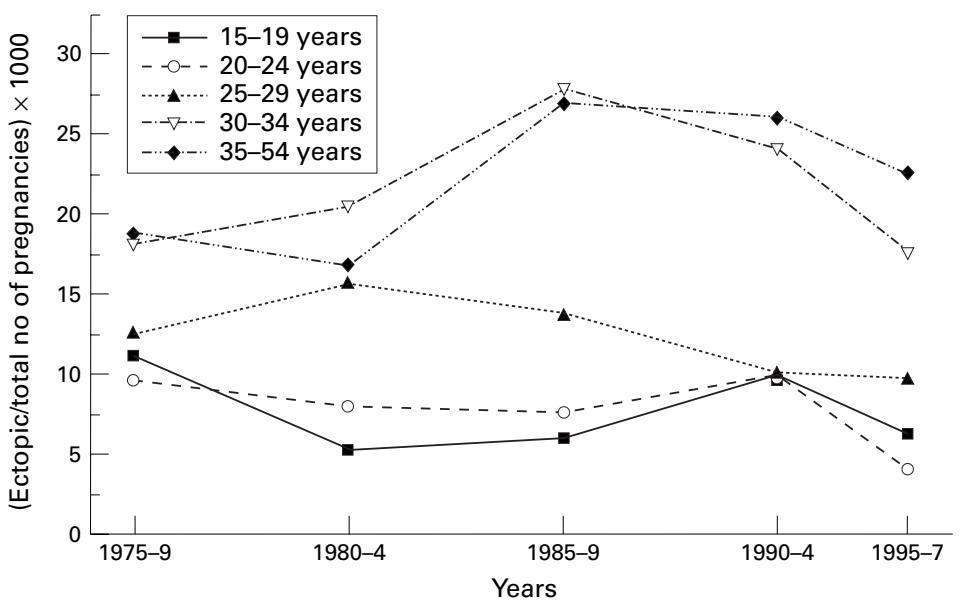

Figure 2 The incidence of ectopic pregnancy (EP) per 1000 pregnancies in Örebro county, catchment area for Örebro Medical Centre Hospital. The patients were divided into five age groups, and incidences were calculated per 5 year period from 1975 to 1994 and the last 3 year period (1995-7).

$\leqslant 24$, whereas the younger age group are responsible for the majority of PID admissions. ${ }^{17}{ }^{19}$ For the first 5 year period only the total EP figures were available and could not be divided into the two age groups. The sharp increase of total EPs in 1975-9 (fig 1) coincided with the highest incidence of 10.0 per 1000 pregnancies during the whole study period in women $\leqslant 24$ years (table 1 ). This also coincided with the highest incidence of PID admissions notified within this age group during the study period. The greatest changes of PID admissions occurred in women of this age group; after 1979 admissions continuously decreased and reached a low of 0.4 in 1996 . With the exception of 1990-4, this coincided with a continuous decrease of EPs within this age group. The decrease was most marked for the past 3 years, and the figures for 1997 corresponded to $41.6 \%$ of those in 1975-9-that is, a reduction of $58.4 \%$.

EP has been shown to be a late sequela of PID $^{4} 17$ this may be further illustrated by the inverse incidence figures presented in table 1 in the two age groups - that is, high PID admissions but relatively low EPs for women $\leqslant 24$ years old and vice versa for those $\geqslant 25$. It can also be seen that a decrease of EPs in women $\leqslant 24$ years old coincided with the decrease of PID admissions in this age group whereas EPs continued to rise in those $\geqslant 25$ years and, in fact, reached two to three times higher incidence figures before a decrease was noted in the early 1990s. A further analysis of EPs in the various age groups $(15-19,20-24,25-29$, etc) showed that the steady increase and the peak incidence were linked to those $\geqslant 30$ years old (fig2). As shown in this figure the EP incidence in women 25-29 years old peaked in 1980-4 - that is, one 5 year period later than for those $\leqslant 24$ years, and one period earlier compared with those $\geqslant 30$ years old. These observations are probably due to cohort effects lending support to the suggestion of a time lag between PID and the occurrence of EP. ${ }^{628}$ After 1989 the EP incidence has decreased steadily in women $\geqslant 25$ years with the lowest rate noted for the last 23 years in 1997-that is, a total reduction of $33.4 \%$.

\section{Discussion}

This study has lent support to the hypothesis that a reduction of PID will be associated with a decline of EP, provided that a certain time lag is taken into account. The decline was greater and more immediate for women $\leqslant 24$ years than for those $\geqslant 25$ years old. There was a two to three times higher EP incidence in women $\geqslant 25$ years of age which is most probably due to a cohort effect as the peak of PID occurred a decade earlier in women $\leqslant 24$ years old.

Although the sites of ectopic pregnancy are many, over $95 \%$ occur in the fallopian tubes. ${ }^{28}$ Furthermore, pathogenesis of EP is multifactorial, ${ }^{14}{ }^{15}$ but the risk increases sevenfold after an attack of acute PID. ${ }^{4}$ It has also been documented that previous PID is the strongest predictor for EP. ${ }^{411517}$ As PID occurs almost exclusively in sexually active women of fertile age, especially in young women $\leqslant 24$ years of age, ${ }^{17}{ }^{19} 24$ a high incidence of this disorder in the community would be likely to be reflected in an increased occurrence of EP, which in fact was documented in several publications in the 1980s and 1990s, ${ }^{4-13}$ and this was also obvious in our study. Correspondingly, a decreased or low incidence of PIDs would be reflected in a decline of EPs. However, there are few studies with this approach.

Even though the present study is on an ecological basis - that is, an aggregate study comparing groups rather than individuals, ${ }^{29}$ our findings lend support to these suggestions. There was a continuous increase of EPs and the beginning of an obvious decline did not occur until two decades after the peak incidence of PIDs and the clear decrease of patients hospitalised for this condition. These observations, together with the rapid increase of EPs in the late 1970s and in the 1980s, two 5 year periods after the clearly elevated incidence of PIDs, lend support to the suggested time lag between the occurrence of PID and the event of EP in the individual. ${ }^{6}{ }^{28}$

EP is generally considered to be most common in women $\geqslant 25$ years of age ${ }^{17}$ which was confirmed in the present study (table 1). A further analysis showed, however, that this was particularly true for those $\geqslant 30$ years (fig 2). The two to three times higher peak incidence of 
EP in 1985-9, compared with 1970-4, was linked to women $\geqslant 30$ years old whereas the peak incidence in women 25-29 years old occurred one previous 5 year period-that is, one 5 year period after the peak of PID. It is also of interest to note that the decrease of EP in women $\leqslant 24$ years coincided with the rapid decline of PID in this age group. Two conclusions can be drawn; firstly, a low PID incidence of PID admissions in young women will be associated with a low incidence of EPs both in young and older women, and, secondly, a high incidence of PID admissions, particularly in young women, will be linked to a high incidence of EPs, one decade or more later on.

As EP is one of the most serious long term sequelae of PID, ${ }^{4112830}$ efforts to reduce this condition will play a big part in strategies for its prevention. It is also proved that PID is not only the most common but also the most serious complication of gonorrhoea and/or genital Chlamydia trachomatis infections, and that a high incidence of these infections in the community is reflected in a high incidence of both clinically overt and clinically silent PID. ${ }^{19-21} 24252831$ Gonococcal PIDs, common in the late 1960 s and early 1970 s, are extremely rare at present. Genital chlamydial infections have reduced significantly during the past decade in Sweden, which has been associated with a significant decrease of the yearly incidence of hospitalised PID patients in our catchment area during the 1980s and 1990s. ${ }^{25}$ These ongoing reductions of clinically overt PIDs have coincided with an obvious decline of EPs in women $\leqslant 24$ years old. This is in agreement with a recently reported ecological study, in which screening for and treatment of genital chlamydial infections was associated with a reduced incidence of EP, especially in the younger age group $\leqslant 24 .^{32}$ This might, in fact, have contributed to the prevention of clinically silent or overt PID as sexually transmitted bacterial infections are the main cause of this disorder in young fertile women. ${ }^{2425} 2831$

We are aware that some early spontaneous abortions and even subclinical $\mathrm{EPs}^{33}$ do not result in medical consultation and will therefore not be registered in hospital records. We believe, however, that the lack of these figures did not influence the general trends to any greater extent.

We also realise that the ratios of EPs to total pregnancies are dependent on both the numerator and the denominator as well as the variations in the size of cohorts of women of child bearing age being exposed to the risk factors of PID. ${ }^{34}$ This may in fact be a plausible explanation for the interruption in the period 1990-4 of the downward trend of EP incidences for women $\leqslant 24$ years of age (table 1 ). We are also aware that the value of our conclusions may be limited as they were related to a restricted geographical area, and based on an ecological study with all its limitations, ${ }^{29}{ }^{35}$ - that is, the incidence of hospitalised PID patients was used as an explanatory variable to EP. However, the trends and the patterns of EP in various age groups in our catchment area in general were similar for
Sweden at large. ${ }^{36}$ Moreover, the decrease in the 1980s and 1990s of overt PID in our area was similar to that in other parts of our country. ${ }^{2325}$ A more or less complete coverage of factors that have influenced the incidence of PID in our catchment area such as the use of contraceptives, more importantly intrauterine devices (IUCDs), and possible confoundersfor example, outpatient management and "silent" PID, has been reported earlier. ${ }^{22} 2425$

Despite the above mentioned limitations and possible confounding factors of the present study and the recent one by Egger et $a l^{22}$ it seems clear that reduction and control of gonorrhoea and genital chlamydial infections will reduce the incidence of PID which in turn will decrease the occurrence of its long term sequelae, more importantly ectopic pregnancy.

We thank the research committee of Örebro County Council for their support of this project.

Contributors: All authors contributed to the design of the study and the final version of the manuscript. FK contributed to study and the final version of the manuscript. FK contributed to data collection and wrote the preliminary draft of the
manuscript; LF contributed to data collection at the beginning of the study period; LB was responsible for the statistical analysis of the project data; DD provided the expertise in the laborasis of the project data; DD provided the expertise in the labora-
tory diagnosis of sexually transmitted organisms, Neisseria gontory diagnosis of sexually transmitted organisms, Neisseria gon-
orrhoeae and Chlamydia trachomatis, and analysis of these data orrhoeae and Chlamydia trachom
during the whole study period.

1 Schneider J, Berger CJ, Cattell C. Maternal mortality due to ectopic pregnancy: a review of 102 deaths. Obstet Gynecol 1977;49:557-61.

2 Chavkin W. The rise in ectopic pregnancy-exploration of possible reasons. Int $\mathcal{F}$ Gynaecol Obstet 1982;20:341-50.

3 Dimitry ES. Ectopic pregnancy: epidemiology, advances in Dimitry ES. Ectopic pregnancy: epidemiology, advances in
diagnosis and management. Br f Clin Path 1992;46:52-4.

diagnosis and management. Br f Clin Path 1992;46:52-4.
4 Weström L, Bengtsson L Ph, Mărdh P-A. Incidence, trends and risks of ectopic pregnancy in a population of women. BMF 1981;282:15-18

5 Coste J, Laumon B, Brémond A, et al. Sexually transmitted diseases as major causes of ectopic pregnancy: results from a large case-control study in France. Fert Steril 1994;62: $289-95$

6 Mäkinen JI. Increase of ectopic pregnancy in Finlandcombination of time and cohort effects. Obstet Gynecol 1989;73:21-24

7 Skjeldestad FE, Kendrick JS, Atrash HK, et al. Increasing county of ectopic pregnancy in one Norwegian county - a population based study.

8 Atrash HK, Hughes JM, Hogue CJR. Ectopic pregnancy in the United States, 1970-1983. In: CDC surveillance
summaries, Aug 1986. MMWR 1986;35(No 2SS):29-37SS.

9 Hockin JC, Jessamine AG. Trends in ectopic pregnancy in Canada. Can Med Assoc f 1984;131:737-40.

10 Bernstein J. Ectopic pregnancy: a nursing approach to excess risk among minority women. $\mathcal{F}$ Obstet Gynecol Neonatal Nurs 1995;24:803-10.

11 Clark K, Baranyai J. Pelvic infection and the pathogenesis of tubal ectopic pregnancy. Aust NZ $\mathcal{f}$ Obstet Gynaecol 1987;27:57-60.

12 Al-Nuaim L, Bamgboye EA, Chowdhury N, et al. Reproductive potential after an ectopic pregnancy. Fertil Steril 1995;64:942-6.

13 Centers for Disease Control. Current trends: ectopic pregnancy-United States, 1990-1992. MMWR 1995;44: 46-8.

14 Pisarska MD, Carson SA, Buster JE. Ectopic pregnancy. Lancet 1998;351:1115-20.

15 Ankum WM, Mol BWJ, Van der Veen F, et al. Risk factors for ectopic pregnancy: a meta-analysis. Fertil Steril 1996;65: 1093-9.

16 Meirik O. Ectopic pregnancy during 1961-78 in Uppsala county, Sweden. Impact of demographic factors on overall incidence. Acta Obstet Gynecol Scand 1981;60:545-8.

17 Hadgu A, Koch G, Weström L. Analysis of ectopic pregnancy data using marginal and conditional models. Statist Med 1997;16:2403-17.

18 Curran JW. Economic consequences of pelvic inflammatory disease in the United States. Am F Obstet Gynecol 1980;138: 848-51.

19 Weström L. Incidence, prevalence, and trends of acute pelvic inflammatory disease and its consequences in industrialized countries. Am $\mathcal{F}$ Obstet Gynecol 1980;138:880-92.

20 Adler MW. Trends for gonorrhea and pelvic inflammatory disease in England and Wales and for gonorrhea in a defined population. Am F Obstet Gynecol 1980;138:901-4.

21 Forslin L, Falk V, Danielsson D. Changes in the incidence of acute gonococcal and nongonococcal salpingitis. A fiveyear study from an urban area of central Sweden. Br F Vener
Dis 1978;54:247-50. 
22 Kamwendo F, Forslin L, Danielsson D. Epidemiology and aetiology of acute non-tuberculous salpingitis: a comparison between the early 1970 s and the early 1980 s with special reference to gonorrhoea and use of intraute

ceptive device. Genitourin Med 1990;66:324-9.
23 Weström L. Decrease in incidence of women treated in hospital for acute salpingitis in Sweden. Genitourin Med 1988; 64:59-63.

24 Kamwendo F, Forslin L, Bodin L, et al. Decreasing incidences of gonorrhea- and chlamydia-associated acute pelvic inflammatory disease: a 25-year study from an urban area of central Sweden. Sex Transm Dis 1996;23:384-91.

25 Kamwendo F, Forslin L, Bodin L, et al. Programmes to reduce pelvic inflammatory disease-the Swedish experience. Lancet 1998;351(suppl III):25-8.

26 Zorn J-R, Risquez F, Cedard L. Ectopic pregnancy. Curr Opin Obstet Gynecol 1992;4:238-45.

27 Shalev ES, Yarom I, Bustan M, et al. Transvaginal sonography as the ultimate diagnostic tool for the management of phy as the ultimate diagnostic tool for the management of 1998;69:62-5.

28 Weström L, Eschenbach D. Pelvic inflammatory disease (PID). In: Holmes KK, Mårdh P-A, Sparling PF, Lemon SM, Stamm mitted diseases. New York, Toronto: McGraw-Hill, Health Professions Division, 1999:783-809.
29 Morgenstern H. Ecologic studies. In: Rothman KJ, Greenland S, eds. Modern epidemiology. Philadelphia: Lippincott-Raven, 1998:459-80.

30 Quan $M$. Pelvic inflammatory disease: diagnosis and management. F Am Board Fam Pract 1994;7:110-23.

31 Scholes D, Stergachis A, Heidrich FE, et al. Prevention of pelvic inflammatory disease by screening for cervical chlamydial infection. N Engl f Med 1996; 334:1362-6.

32 Egger M, Low N, Smith GD, et al. Screening for chlamydial infections and the risk of ectopic pregnancy in a county in infections and the risk of ectopic pregnancy in a count

33 Robson SJ, O'Shea RT. Undiagnosed ectopic pregnancy: a retrospective analysis of 31 'missed' ectopic pregnancies at a teaching hospital. Aust NZ Obstet Gynaecol 1996;36: $182-5$.

34 Mäkinen J, Rantala M, Vanha-Kämppä O. A link between the epidemic of ectopic pregnancy and the "baby-boom" cohort. Am f Epidemiol 1998;148:369-74.

35 Greenland S, Robins J. Invited commentary: ecologic studies - biases, misconceptions, and counterexamples. Am studies-biases, misconception

36 Thorburn J. Is the epidemic of ectopic pregnancy over in Sweden? A report on present incidence and mortality. Läkartidningen 1995;92:4701-6. (Swedish, summary in English) 